* Mestre e Doutorando em Direito (Finanças Públicas, Tributação \& Desenvolvimento) pela Universidade do Estado do Rio de Janeiro (UERJ). Pós-graduado em Direito da Administração Pública pela Universidade Federal Fluminense (CEDAP/ UFF). Bacharel em Ciências Jurídicas e Sociais pela Universidade Federal do Rio de Janeiro (UFRJ). Ex-Assessor de Procurador Regional da República (MPF/PRR2). Procurador da Fazenda Nacional. daniel.marins@gmail.com

** Mestre e Doutor em Direito Público pela Universidade do Estado do Rio de Janeiro (UERJ). Graduação em Direito pela Universidade do Estado do Rio de Janeiro. Procurador do Município do Rio de Janeiro. Professor adjunto de Direito Financeiro da Universidade do Estado do Rio de Janeiro (graduação, mestrado e doutorado). ggamav@gmail.com

\section{A Autonomia Federativa e o Problema DA UNANIMIDADE NOS CONVÊNIOS DO CONFAZ}

Federative Autonomy And the Problem of UNANIMITY IN CONFAZ's AgREEMENTS

\section{Daniel Vieira Marins* Gustavo da Gama Vital de Oliveira**}

Como citar: MARINS, Daniel Vieira. OLIVEIRA, Gustavo da Gama Vital de. A autonomia federativa e o problema da unanimidade nos convênios do CONFAZ. Revista do Direito Público, Londrina, v. 12 , n. 2, p. 250-272, ago. 2017. DOI: $10.5433 / 1980-511 X .2017 \mathrm{v} 12 \mathrm{n} 2 \mathrm{p} 250$

Resumo: Os autores do artigo questionam a necessidade de haver decisões unânimes nos convênios do Conselho Nacional de Política Fazendária (CONFAZ) sobre a concessão de benefícios ou incentivos fiscais de ICMS. Para tanto, é apresentado o posicionamento do STF sobre o tema, o procedimento legislativo adotado pelos Estados para enfrentar as declarações de inconstitucionalidade, a ocorrência da chamada "inconstitucionalidade útil", bem como é examinada a Lei Complementar $n^{\circ} 24 / 75$. Além disso, é realizada uma análise crítica do perigo de se perpetuar a "ditadura da minoria" na Federação brasileira. Somando-se a isso, uma abordagem histórica é realizada, destacando-se 
o posicionamento doutrinário sobre a questão. Por fim, são apresentadas sugestões para se enfrentar o problema da unanimidade nos convênios do CONFAZ.

Palavras-Chave: Guerra fiscal. Convênio do CONFAZ. ICMS. Inconstitucionalidade útil. Ditadura da minoria.

Abstract: The authors of the research paper in question analyze the need for unanimous decisions in the agreements of the Brazilian National Finance Policy Council (CONFAZ), as it can grant ICMS tax benefits and incentives. To this end, we explore the Brazilian Supreme Court's - also known in Portuguese as the "Supremo Tribunal Federal" - position on this matter; the legislative procedure adopted by states when dealing with declarations of unconstitutionality; the occurrence of the "useful unconstitutionality"; as well as examining the Brazilian Law n. 24/75. Additionally, we make a critical analysis of the dangerous perpetuation of the "dictatorship of the minority" present in the Brazilian Federation. Moreover, we utilized a historical approach, highlighting legal scholars' views on this issue and finally, we suggest solutions for the problem of unanimity in the CONFAZ's agreements.

Keywords: Fiscal war. CONFAZ's agreements. ICMS. Useful unconstitutionality. Dictatorship of the minority. 


\section{INTRODUÇÃO}

Há muitos anos, os estados-membros têm aprovado leis e decretos concedendo benefícios e incentivos fiscais no que tange ao imposto sobre operações relativas à circulação de mercadorias e sobre prestações de serviços de transporte interestadual e intermunicipal e de comunicação (ICMS). Diminuições de alíquotas, reduções da base de cálculo, isenções, créditos presumidos, diferimentos de longo prazo, dentre outros, foram aprovados na esfera estadual, fazendo com que houvesse uma diminuição imediata da carga tributária e, por conseguinte, fossem atraídos novos investimentos para o Estado.

Ocorre que, segundo a Lei Complementar $n^{\circ}$. 24/75, a "[...] concessão de benefícios dependerá sempre de decisão unânime dos Estados representados [...]" (art. $2^{\circ}, \S 2^{\circ}$ ), de modo que, formalmente, todos os decretos e leis estaduais que concedam benefícios e incentivos fiscais sem obedecer às regras em debate não possuem validade (BRASIL, 1975). Vale dizer, antes de se estabelecer uma regra interna que fixe novas modalidades de benefício ou incentivo fiscal de ICMS, o governo subnacional necessita de uma autorização prévia do Conselho Nacional de Política Fazendária (CONFAZ), a qual deverá ser realizada por meio de uma decisão unânime.

Esse sempre foi o posicionamento do Supremo Tribunal Federal (STF). Aliás, desde a promulgação da Constituição de 1988, o Tribunal julgou procedente o pedido de dezenas de ações diretas de inconstitucionalidade referentes à chamada "guerra fiscal" do ICMS, aplicando a exigência prevista no art. $155, \S 2^{\circ}$, XII, “g”, da Constituição da República a partir das diretrizes fixadas pela Lei Complementar $n^{\circ}$ $24 / 75$. 
Não obstante a jurisprudência da Suprema Corte e a realização periódica de reuniões do Conselho Nacional de Política Fazendária, diversos Estados mantiveram a mesma conduta: continuaram publicando atos normativos estaduais concedendo benefícios ou incentivos fiscais de ICMS, independentemente de decisões unânimes do CONFAZ e das demais regras previstas no art. $2^{\circ}$ da Lei Complementar $n^{\circ} 24 / 75$.

Mas qual seria o motivo pelo qual inúmeros Estados ainda publicam leis e decretos concedendo benefícios ou incentivos fiscais de ICMS sem a existência prévia de decisão unânime em convênios do CONFAZ, se o STF, reiteradamente, já decidiu que esta conduta é contrária à Constituição? O problema envolveria apenas uma questão de ineficácia, ou eficácia limitada, das decisões do Supremo? Ou haveria obstáculos relativos à forma de tomada de decisão no Conselho Nacional de Política Fazendária?

\section{A INTERPRETAÇÃO DO SUPREMO TRIBUNAL FEDERAL QUANTO AO ART. 155, § 2 $2^{\circ}$ XII, “g”, DA CONSTITUIÇÃO E A CHAMADA "INCONSTITUCIONALIDADE ÚTIL"}

A orientação jurisprudencial do Supremo Tribunal Federal no sentido de que a instituição de benefícios e incentivos fiscais relativos ao ICMS só pode ser realizada com base em convênio interestadual, na forma do art. 155, $\S 2^{\circ}, \mathrm{XII}, \mathrm{g}$, da CR/88 e da Lei Complementar $\mathrm{n}^{\circ}$ 24/75 tem sido reiterada desde a Constituição de 1988. Dispositivos de Constituições estaduais e leis dos Estados do Paraná (ADI 4481/PR, rel. Ministro Roberto Barroso, julgado em 11.03.2015; ADI 2688/PR, rel. Ministro Joaquim Barbosa, julgado em $1^{\circ} .06 .2011$; ADI 3803/PR, rel. Ministro Cezar Peluso, julgado em $1^{\circ} .06 .2011$ ), do Mato Grosso 
do Sul (ADI 3794 ED/PR, rel. Ministro Roberto Barroso, julgado em 18.12.2014), do Amazonas (ADI 4635 MC-AgR-Ref/SP, rel. Ministro Celso de Mello, julgado em 11.12.2014), do Mato Grosso (ADI 4276/ MT, rel. Ministro Luiz Fux, julgado em 20.08.2014), do Rio de Janeiro (ADI 773/RJ, rel. Ministro Gilmar Mendes, julgado em 20.08.2014; ADI 2376/RJ, rel. Ministro Marco Aurélio, julgado em $1^{\circ} .06 .2011$; ADI 3664/RJ, rel. Ministro Cezar Peluso, julgado em $1^{\circ} .06 .2011$ ), do Ceará (ADI 429/CE, rel. Ministro Luiz Fux, julgado em 20.08.2014), de Santa Catarina (ADI 2345/SC, rel. Ministro Cezar Peluso, julgado em 30.06.2011), do Pará (ADI 1247/PA, rel. Ministro Dias Toffoli, julgado em $1^{\circ} .06 .2011$ ), do Espírito Santo (ADI 3702/ES, rel. Ministro Dias Toffoli, julgado em $1^{\circ} .06 .2011$ ), de São Paulo (ADI 4152/SP, rel. Ministro Cezar Peluso, julgado em $1^{\circ}$.06.2011), do Rio Grande do Norte (ADI 2866/RN, rel. Ministro Gilmar Mendes, julgado em 12.05.2010) e do Distrito Federal (ADI 2549/DF, rel. Ministro Ricardo Lewandowski, julgado em $1^{\circ} .06 .2011$ ), por exemplo, já foram objeto de ações diretas de inconstitucionalidade (ADI), tendo o Supremo Tribunal Federal julgado procedente os pedidos feitos pelos requerentes, tendo, em certos casos, declarado até a "perda do objeto" (leia-se, falta de interesse de agir), em razão da posterior alteração legislativa do dispositivo legal questionado.

Ocorre que, ante a decisão que declara a inconstitucionalidade do dispositivo legal, os estados-membros costumam editar novas leis criando benefícios ou incentivos fiscais de ICMS, substituindo as anteriores, declaradas inconstitucionais. Assim, a eficácia da decisão do STF torna-se limitada, pois a legislação questionada no Tribunal ou é substituída por outra durante o trâmite da ação (o que gera a falta do interesse de agir), ou, apesar de ser excluída do plano normativo, dá lugar a uma nova lei (ou mesmo a uma emenda à Constituição Estadual) que 
acaba por regular a matéria de maneira semelhante.

Esse quadro de eficácia altamente limitada das decisões do STF, quanto às declarações de inconstitucionalidade referentes à criação de benefícios ou incentivos fiscais de ICMS, faz com que os estadosmembros continuem a publicar leis que, na verdade, contrariam o art. 155, $\S 2^{\circ}$, XII, “g”, da Constituição da República e a Lei Complementar n ${ }^{\circ}$ 24/75 (BRASIL, 1975, 1988). Tal como se extrai das decisões proferidas nas ações diretas de inconstitucionalidade descritas anteriormente, a imensa maioria dos estados se mantém promulgando leis nesse sentido, o que gera um quadro em que a "inconstitucionalidade" se torna a regra. Vale dizer, o comportamento contrário ao entendimento fixado pelo STF se transformou em conduta comum entre os estados-membros.

Por conseguinte, os estados-membros acabam por se beneficiar da chamada "inconstitucionalidade útil", isto é, da conduta ou atividade que, mesmo sendo declarada inconstitucional, gera efeitos concretos para os agentes a ela vinculados. No caso em tela, os Estados, mesmo já sabendo do entendimento do STF sobre o tema, criam leis que geram benefícios ou incentivos fiscais de ICMS e as aplicam até o momento em que são declaradas inconstitucionais, sendo que os contribuintes favorecidos pela legislação também se aproveitam das benesses legais. Como não há qualquer sanção concreta (salvo a retirada da lei do ordenamento jurídico), os estados continuam a criar novas leis e os contribuintes a usufruir delas.

Não foi à toa que o Ministro Marco Aurélio, no julgamento da ADI 351/RN, fez um alerta sobre os perigos da "inconstitucionalidade útil", tendo em vista que este recente fenômeno pode, indiretamente, incentivar as assembleias legislativas a criar leis à margem da Constituição da República: 
De qualquer forma, revela-se necessário resistir sempre à modulação do pronunciamento do Supremo quando assentado o conflito de certa lei com o Diploma Maior. Toda norma editada em desarmonia com a Carta da República é nula e, portanto, não se tem como mitigar a eficácia da Constituição Federal. Além desse aspecto, há outro: o viés estimulante. A partir do momento em que o Supremo não declara - como deve fazê-lo - inconstitucional uma lei desde o nascedouro, acaba por incentivar as casas legislativas do Brasil a editarem normas à margem da Carta Federal, para que subsistam, com a passagem do tempo, as situações constituídas - que, sob o ângulo do aperfeiçoamento, assim não se mostram -, as quais, posteriormente, serão endossadas, muito embora no campo indireto, presente a modulação. Acaba por surgir instituto novo, como já ressaltei no Plenário - o da inconstitucionalidade útil -, para o que, aliás, contribui a morosidade da máquina judiciária (ADI 351/RN, rel. Ministro Marco Aurélio, julgado em 14.05.2014) (BRASIL, 2014).

Na prática, portanto, verifica-se a pouca ou nenhuma efetividade da regra do art. $8^{\circ}$, inciso II, da Lei Complementar $n^{\circ} 24 / 75$, que determina a exigibilidade do ICMS não pago ou a ineficácia de lei ou ato que conceda remissão do débito correspondente, na hipótese de concessão de benefício fiscal sem a observância da regra de unanimidade prevista da Lei Complementar.

O fenômeno da "inconstitucionalidade útil" cria uma realidade paradoxal: a concessão de benefícios e incentivos de ICMS (vedada na hipótese de violar o art. 155, § 2 , XII, "g", da CR/88) se transforma na realidade padrão dos estados-membros, sendo a exceção os casos em que 
os governos subnacionais não editam leis neste sentido (BRASIL, 1988).

Daí o porquê de os estados-membros estarem, desde a Constituição de 1988, em um círculo vicioso: criam-se leis que, previamente, já sabe que serão declaradas inconstitucionais e, com a eventual declaração de inconstitucionalidade pelo STF, são criadas novas leis, as quais, sendo impugnadas no Supremo, são novamente alteradas ou substituídas por outras de conteúdo semelhante.

A possibilidade de reconhecimento da eficácia ex nunc da declaração de inconstitucionalidade de lei de benefício fiscal em desacordo com a Lei Complementar $n^{\circ} 24 / 75$, ou seja, acatando os efeitos produzidos pela lei até a data do julgamento, tal como reconhecido em decisão recente o Pleno do STF, também é suscetível de contribuir para o quadro mencionado. Nesse aspecto, deve-se destacar o acórdão exarado no julgamento da ADI 4481:

I. TRIBUTÁRIO. LEI ESTADUAL QUE INSTITUI BENEFÍCIOS FISCAIS RELATIVOS AO ICMS. AUSENCIA DE CONVÊNIO INTERESTADUAL PRÉVIO. OFENSA AO ART. $155, \S 2^{\circ}$, XII, g, DA CF/88. II. CONTROLE DE CONSTITUCIONALIDADE. MODULAÇÃO DOS EFEITOS TEMPORAIS. 1.A instituição de benefícios fiscais relativos ao ICMS só pode ser realizada com base em convênio interestadual, na forma do art. $155, \S 2^{\circ}, X I I, g$, da CF $/ 88$ e da Lei Complementar $n^{\circ}$ 24/75. 2. De acordo com a jurisprudência do STF, o mero diferimento do pagamento de débitos relativos ao ICMS, sem a concessão de qualquer redução do valor devido, não configura benefício fiscal, de modo que pode ser estabelecido sem convênio prévio. 3. A modulação dos efeitos temporais da decisão que declara a inconstitucionalidade decorre da ponderação entre a disposição constitucional tida 
por violada e os princípios da boa-fé e da segurança jurídica, uma vez que a norma vigorou por oito anos sem que fosse suspensa pelo STF. A supremacia da Constituição é um pressuposto do sistema de controle de constitucionalidade, sendo insuscetível de ponderação por impossibilidade lógica. 4. Procedência parcial do pedido. Modulação para que a decisão produza efeitos a contatar da data da sessão de julgamento. (ADI 4481, rel. Ministro Roberto Barroso, Tribunal Pleno, julgado em 11.03.2015, DJe-092, divulgado em 18.05.2015, publicado em 19.05.2015) (BRASIL, 2015).

Para combater a "inconstitucionalidade inútil" decorrente da limitada eficácia da declaração de inconstitucionalidade nessas hipóteses, o Supremo Tribunal Federal aventou a possibilidade de criar uma Súmula Vinculante sobre a matéria, cujo conteúdo, em linhas gerais, afirmaria que qualquer isenção, incentivo, redução de alíquota ou de base de cálculo, crédito presumido, dispensa de pagamento ou outro benefício fiscal relativo ao ICMS, concedido sem prévia aprovação em convênio celebrado no âmbito do CONFAZ, seria inconstitucional.

Para os defensores da edição da súmula vinculante, haveria manifesto ganho de celeridade para que os estados prejudicados com a concessão de benefícios ou incentivos fiscais inconstitucionais pudessem questioná-los no Supremo Tribunal Federal por meio de reclamação, não sendo necessário trilhar o caminho mais demorado das ações diretas de inconstitucionalidade.

Contudo, além de subsistir o problema da sanção em caso de desobediência à Súmula Vinculante, o conteúdo do verbete ainda prejudica as propostas de leis estaduais que visem a cuidar de benefícios ou incentivos fiscais de ICMS que não se relacionem com a chamada 
"guerra fiscal" (justamente por sequer envolverem uma situação envolvendo competição tributária). Como exemplos, deve-se destacar o julgamento da ADI 3421/PR (rel. Ministro Marco Aurélio, julgado em 05.05.2010) ${ }^{1}$, em que se tratou de benefícios fiscais de ICMS relacionados a serviços públicos voltados para igrejas e tempos religiosos, e os benefícios ou incentivos fiscais referentes às atividades econômicas que, por razões de fato, não podem ser realizadas em outros locais (v.g., exploração mineral).

Por sinal, ao analisar as atividades de exploração mineral, Ricardo Lodi Ribeiro (2012, p. 145) observa que a natureza da atividade desenvolvida pode interferir na possibilidade fática de existir uma "guerra fiscal", pois algumas atividades produtivas são limitadas geograficamente, sendo inviável a concessão de benefícios ou incentivos fiscais por outro Estado-membro:

Desenvolvendo um pouco mais essa ideia, baseada na preservação da autonomia local sempre que a sua restrição não seja indispensável à preservação do federalismo fiscal no plano horizontal, conclui-se que os convênios não são necessários em relação aos benefícios fiscais vinculados à exploração de atividade que, pelas suas características, não poderia ser efetivada em outro Estado, como a extração mineral, por exemplo, pois por ser a atividade circunscrita a determinado limite especial, os benefícios concedidos por outros Estados não teriam

1 Ementa: ICMS - SERVIÇOS PÚBLICOS ESTADUAIS PRÓPRIOS, DELEGADOS, TERCEIRIZADOS OU PRIVATIZADOS DE ÁGUA, LUZ, TELEFONE E GÁS - IGREJAS E TEMPLOS DE QUALQUER CRENÇA - CONTAS - AFASTAMENTO - "GUERRA FISCAL” - AUSÊNCIA DE CONFIGURAÇÃO. Longe fica de exigir consenso dos Estados a outorga de benefício a igrejas e templos de qualquer crença para excluir o Imposto sobre Circulação de Mercadorias e Serviços nas contas de serviços públicos de água, luz, telefone e gás.” (ADI 3421/PR, rel. Ministro Marco Aurélio - Tribunal Pleno, julgado em 05.05.2010, DJe-096 27.05.2010, publicado em 28.05.2010) (BRASIL, 2010). 
o condão de afastar o empreendedor do local onde a operação precisa ser desenvolvida, não havendo que se falar em guerra fiscal ensejadora da limitação da autonomia local (RIBEIRO, 2012, p. 145)

\section{A EXIGÊNCIA DE UNANIMIDADE NAS DECISÕES DO CONFAZ E A "DITADURA DA MINORIA"}

Não obstante a eficácia limitada das decisões do Supremo Tribunal Federal sobre os casos envolvendo a "guerra fiscal", há outro fator que parece ser o principal motivo de tantos estados-membros ignorarem os convênios do CONFAZ e o posicionamento da Corte Constitucional: a exigência de unanimidade nas decisões do Conselho Nacional de Política Fazendária.

De acordo com o art. $2^{\circ}, \S 2^{\circ}$, da Lei Complementar n ${ }^{\circ} 24 / 75$, a "[...] concessão de benefícios dependerá sempre de decisão unânime dos Estados representados [...]" (BRASIL, 1975). Ou seja, nota-se que a exigência legal parte da premissa de que, por ser o ICMS um tributo com reflexos fiscais e econômicos em outras Unidades Federativas, seria essencial que todos os governos subnacionais concordassem com a criação do benefício ou incentivo de ICMS. A ideia principal seria que os interesses de todos os estados-membros devem ser respeitados, impedindo-se privilégios ou prejuízos dirigidos a alguns governos subnacionais.

De início, a proposta da unanimidade nos convênios parece ser sedutora, mas, na prática de tomadas das decisões, cria-se um modelo em que se consolida uma espécie de "ditadura da minoria". Isto é, basta que pouquíssimos estados-membros, ou mesmo um único governo subnacional, não concordem com a proposta de benefício ou incentivo 
fiscal de ICMS a ser criada que a inovação legislativa é automaticamente rejeitada. Em suma, sob o argumento da defesa da harmonia fiscal e econômica, estimula-se um ambiente em que qualquer ideia nova atinente a benefícios ou incentivos fiscais de ICMS seja considerada condenável e, portanto, proibida, tão somente em razão da vontade da minoria dos Estados-membros. ${ }^{2}$

Sob essa ótica, a imposição da unanimidade na decisão promove a deterioração do pacto federativo, minando a relação de cooperação entre os estados-membros necessária para a manutenção da federação e para a autonomia administrativa dos governos subnacionais. Nesse aspecto, assim observa Tércio Sampaio Ferraz Junior (2012, p. 16):

$\mathrm{Na}$ verdade, um pacto federativo com base em unanimidade/direito de veto lida mal com o equilíbrio entre maioria e minoria e transporta - mal -, para o plano público, uma concepção contratualista privada (na qual existe, por exemplo, o direito de retirada), mas que não se coaduna com uma concepção federalista do Estado democrático, pois subordina a vontade de todos à vontade de um (mediante o poder hegemônico do veto), em nome de uma racionalidade superior e incontestável (grifo do autor).

Vale dizer, em um Estado Democrático de Direito, os governos subnacionais não podem se tornar reféns de decisões com poder de veto de um ou alguns Estados-membros, sob pena de se descaracterizar o conceito de Federação, como se esta fosse um mero acordo entre particulares. Em um Estado federal, exigir um formato de decisão baseado na unanimidade, tal como ocorre nos convênios do Conselho Nacional de

2 A Arguição de Descumprimento de Preceito Fundamental 198 (Rel. Ministro Dias Toffoli), pendente de julgamento, questiona a compatibilidade da regra de unanimidade para a concessão de benefícios fiscais do ICMS com a Constituição de 1988. 
Política Fazendária sob a égide da Lei Complementar $n^{\circ} 24 / 75$, significa aderir a um modelo autoritário e centralizador, o qual não se coaduna com as diretrizes democráticas estabelecidas pela Constituição da República de 1988 (FERRAZ JUNIOR, 2012, p. 16).

Por sinal, sobre os prejuízos da excessiva centralização em um modelo federal e da supressão da autonomia dos Estados-membros, assim conclui Ricardo Lodi Ribeiro (2012, p. 145-146):

[...] De fato, exigir a unanimidade entre os Estados para a aprovação de qualquer benefício fiscal equivale a quase sempre inviabilizar qualquer proposta desoneradora, abrindo espaço para medidas unilaterais abusivas por parte dos Estados. É preciso dotar os Estados da possibilidade de estabelecerem sua política fiscal em seu principal imposto e, ao mesmo tempo, coibir o exercício do abuso de direito caracterizado como guerra fiscal.

Diante do cenário instituído pela imposição da unanimidade nos convênios exigida pelo art. $2^{\circ}, \S 2^{\circ}$, da Lei Complementar $n^{\circ} 24 / 75$, duas modalidades de conflito foram surgindo após a Constituição de 1988 e, em especial, depois do "Plano Real", consolidado no primeiro mandato do Presidente Fernando Henrique Cardoso (1994-1998): (i) Estados do Sul e Sudeste questionando legislações dos Estados do Nordeste e do Centro Oeste; e (ii) Estados fortes em determinados ramos da economia impugnando legislações de Estados pouco desenvolvidos economicamente. Ambas as modalidades de conflito dominaram o que veio a se tornar a chamada "guerra fiscal", que vem causando turbulências políticas e econômicas desde então.

Caso não houvesse a exigência de unanimidade nas decisões 
do CONFAZ referentes aos benefícios ou incentivos fiscais de ICMS, haveria, minimamente, como os estados-membros interessados em atrair mais investimentos ou em desenvolver determinada atividade econômica darem efetividade às suas políticas públicas. Vale dizer, governos subnacionais de regiões tradicionalmente menos desenvolvidas economicamente ou que pretendam desenvolver uma atividade econômica específica em razão (a) de sua alta relevância tecnológica (v.g., informática, pesquisas em biologia ou farmacologia, engenharia eletrônica) ou (b) de necessidades regionais ( v.g., agricultura, piscicultura ou pecuária em localidades carentes desses setores) poderiam formular programas que, mesmo sendo pontualmente limitados pelos interesses dos demais Estados-membros, seriam aplicados.

No entanto o que se tem é a polarização de grupos dentro das duas modalidades de conflito descritas anteriormente, incentivando-se uma espécie de autotutela por parte dos governos subnacionais: sendo impossível apresentar programas de benefícios ou incentivos fiscais de ICMS com aval dos demais governos, cada Estado-membro, sponte propria, cria a sua legislação.

Tal postura de autotutela por parte de cada ente subnacional ainda se verifica quando o Estado de destino das mercadorias considera, por decisão própria, inconstitucional o benefício fiscal conferido pelo Estado de origem (mesmo sem o julgamento de uma ação direta de inconstitucionalidade pelo STF) e efetua a glosa do crédito apresentado pelo contribuinte, exigindo o tributo de forma integral.

Trata-se de procedimento que enfrenta críticas da doutrina ${ }^{3}$ e

3 "O estorno do crédito pelo Estado de destino com a consequente arrecadação do valor correspondente é um atentado ao traçado das competências tributárias definido pela Constituição, tendo em vista que o Estado destinatário acaba por arrecadar tributo que não é atribuído a ele, mas sim à unidade federada de 
que não é aceito pela jurisprudência do Superior Tribunal de Justiça ${ }^{4}$, havendo ainda repercussão geral com julgamento de mérito pendente de análise no Supremo Tribunal Federal (RE 628075, rel. Ministro Joaquim Barbosa, julgado em 13.10.2011).

Ante o ambiente de crise fiscal em debate, dois caminhos poderiam ser percorridos para se enfrentar o problema: ou se alteraria o art. $2^{\circ}, \S 2^{\circ}$, da Lei Complementar $n^{\circ} 24 / 75$, acabando com a exigência da unanimidade nos convênios, ou se criaria outro modelo legislativo para atender à orientação do art. 155, § 2 , XII, “"g”, da CR/88 (BRASIL, 1975, 1988).

Em modelo que tenta aglutinar os dois caminhos, há projeto de lei complementar em trâmite no Senado (PLS 130/2014), cujo substitutivo (Emenda $\mathrm{n}^{\circ} .1$ da Comissão de Assuntos Econômicos - CAE) assim prevê:

Art. $1^{\circ}$ Mediante convênio celebrado nos termos da Lei Complementar ${ }^{\circ}$ 24, de 7 de janeiro de 1975, os Estados e o Distrito Federal poderão deliberar sobre a:

I - remissão dos créditos tributários, constituídos ou não, decorrentes das isenções, incentivos e benefícios fiscais ou financeiro-fiscais instituídos em desacordo com o disposto no art. $155, \S 2^{\circ}$, XII,

origem das mercadorias." (VIANA, 2016, p. 29).

4 "RECURSO EM MANDADO DE SEGURANÇA. TRIBUTÁRIO E ADMINISTRATIVO. GUERRA FISCAL. TENSÃO CRIADA ENTRE OS SISTEMAS TRIBUTÁRIOS DOS ESTADOS FEDERADOS DO BRASIL. CONFAZ. NECESSIDADE DE SOLUÇ̃̃O PELA VIA JURISDICIONAL, COM AFASTAMENTO DA VIAADMINISTRATIVA. RECURSO PROVIDO. 1. A impropriamente denominada guerra fiscal é um mecanismo legítimo dos Estados periféricos do capitalismo brasileiro, para tornar atraentes as operações econômicas com as empresas situadas em seus territórios; a exigência de serem as Resoluções do CONFAZ aprovadas por unanimidade dá aos Estados centrais o poder de veto naquelas deliberações, assim cirando a tensão entre os sistemas tributários dos Estados Federados do Brasil. 2. Somente iniciativas judiciais, mas nunca as apenas administrativas, poderão regular eventuais conflitos de interesses (legítimos) entre os Estados periféricos e os centrais do sistema tributário nacional, de modo a equilibrar as relações econômicas entre eles, em condições reciprocamente aceitáveis. 3. Recurso provido." (RMS 33.524/PI, rel. Ministra ELIANA CALMON, rel. p/ acórdão Ministro NAPOLEÃO NUNES MAIA FILHO, Primeira Seção, julgado em 28.08.2013, DJe 07.03.2014) (BRASIL, 2014b). 
“g”, da Constituição Federal, por legislação estadual publicada até a data de início de produção de efeitos desta Lei Complementar; e

II - reinstituição das isenções, incentivos e benefícios referidos no inciso I que ainda se encontrem em vigor. Art. $2^{\circ} \mathrm{O}$ convênio a que se refere o art. $1^{\circ}$ poderá ser aprovado e ratificado com o voto favorável de, no mínimo:

I - dois terços das unidades federadas; e

II - um terço das unidades federadas integrantes de cada uma das cinco regiões do País ${ }^{5}$. (BRASIL, 2014).

Um grande avanço do projeto de lei complementar do Senado, na forma do substitutivo, é que afasta o poder de veto da minoria, criando um espaço mais amplo para o debate sobre o conteúdo da legislação e não meramente sobre a exclusão, a priori, do benefício ou incentivo fiscal a ser criado. No quadro atual, sequer é possível o diálogo e a apresentação de propostas que visem ao aperfeiçoamento da lei pretendida pelo governo subnacional (típico da relação de coordenação em federações), de modo que se conquiste o apoio da maioria. Hoje, antes mesmo do debate propositivo, a matéria já é excluída, de forma que se cristaliza o posicionamento do "tudo ou nada". Assim, caso seja dado prosseguimento às ideias constantes do PLS 130/2014, será possível que ocorra a diminuição dos conflitos federativos no segmento da competição tributária, em especial na esfera da chamada "guerra fiscal".

Paralelamente, percebe-se que a proposta de lei complementar do Senado busca, tão somente, alterar e acrescentar critérios ao modelo já fixado pela Lei Complementar $n^{\circ}$ 24/75. Contudo seria interessante questionar o próprio modelo estabelecido em 1975. Isto porque o formato

$5 \mathrm{O}$ quadro comparativo entre o projeto de lei complementar e seu substitutivo, encaminhado à CAE (BRASIL, 2014a). 
de convênio firmado pelo CONFAZ se reporta a um período histórico que teria sido o auge da centralização do autoritarismo militar, em que o governo federal se sobrepunha à autonomia estadual (RIBEIRO, 2012, p. 145). Daí o porquê de Fernando Rezende ressaltar que:

O Conselho Nacional de Política Fazendária (CONFAZ) sobreviveu à reforma constitucional de 1988, mas sem condições efetivas para coordenar a política tributária estadual e atuar em defesa da preservação da base tributária dos estados. Fortaleceu-se tecnicamente; contudo, perdeu a condição de atuar politicamente com base numa visão estratégica voltada à preservação da autonomia financeira e à promoção da harmonia federativa (REZENDE, 2016, p. 57).

Sob o perfil institucional autoritário da Federação criado pela Constituição de 1967, na forma da Emenda Constitucional n 1 de 1969, foi implementado um regime federativo que, na esfera tributária, garantiu a supremacia da União sobre os Estados-membros e os Municípios (FERRAZ JUNIOR, 2012, p. 16-17). A subserviência dos Estados era tamanha que sequer havia a possibilidade de as Assembleias Legislativas rejeitarem os termos do convênio firmado pelo governo estadual, o que criou uma posição de superioridade do Poder Executivo em detrimento do Poder Legislativo que persiste até os dias atuais.

Sob esse prisma, o modelo de unanimidade nas decisões do CONFAZ referentes a benefícios ou incentivos fiscais de ICMS revelase dissonante com o Estado Democrático de Direito, inaugurado com a Constituição de 1988, pois a estrutura de federação instituída pelo Poder Constituinte envolve a aplicação da democracia econômica, social e cultural como objetivo da democracia política (FERRAZ JUNIOR, 2012, 
p. 19), o que enseja a efetiva autonomia financeira e administrativa dos governos subnacionais. Logo, nota-se que é altamente questionável, sob uma República Federativa em que se tem como um dos fins fundamentais reduzir as igualdades sociais e regionais (art. $3^{\circ}$, inc. III, da $\mathrm{CR} / 88$ ), que o estado-membro seja impedido de adotar políticas fiscais que viabilizem a atração de investimentos e projetos em razão de um ou alguns governos subnacionais serem contrários à lei daquele Estado.

Assim, para que se crie um modelo eficaz e compatível com as diretrizes fixadas pelo legislador constituinte de 1988, deve-se enfrentar a questão da concessão dos benefícios ou incentivos fiscais por uma das seguintes formas: (i) ou se altera o art. $2^{\circ}, \S 2^{\circ}$, da Lei Complementar $n^{\circ} 24 / 75$, acabando com a exigência da unanimidade nos convênios do CONFAZ sobre o tema, abrindo-se espaço para a participação democrática dos estados-membros e dando relevo à cooperação na Federação; (ii) ou se institui outro modelo legislativo para atender à orientação do art. $155, \S 2^{\circ}$, XII, “g”, da CR/88, criando-se um novo espaço de ação para os governos subnacionais, como, por exemplo, na hipótese de haver protocolos firmados entre os estados-membros ou câmaras de conciliação em que também houvesse a participação da União como membro mediador dos conflitos federativos entre os entes subnacionais.

\section{CONCLUSÃO}

Percebe-se que há dois motivos pelos quais diversos governos subnacionais ainda publicam leis e decretos concedendo benefícios ou incentivos fiscais de ICMS em dissonância com a orientação jurisprudencial do Supremo Tribunal Federal. 
Em primeiro lugar, a eficácia das decisões do STF sobre a questão é altamente limitada, pois, ante a decisão que declara a inconstitucionalidade do dispositivo legal, os estados-membros promulgam novas leis criando benefícios ou incentivos fiscais de ICMS, substituindo as anteriores, declaradas inconstitucionais. Assim, a legislação questionada no Supremo Tribunal Federal ou é substituída por outra durante o trâmite da ação (o que gera a "perda do objeto"), ou, apesar de ser excluída do plano normativo, dá lugar a uma nova lei, a qual acaba por regular a matéria de maneira semelhante. Esse quadro de realidade faz com que a "inconstitucionalidade" se torne a regra entre os governos subnacionais. Vale dizer, o comportamento contrário ao entendimento fixado pelo STF se transformou na conduta aceita entre os estados-membros. Com isso, os Estado acabam por se beneficiar da chamada "inconstitucionalidade útil", isto é, da conduta ou atividade que, mesmo sendo declarada inconstitucional, gera efeitos concretos para os agentes a ela vinculados. Isto porque os governos subnacionais, mesmo já sabendo do entendimento do Supremo Tribunal Federal sobre o tema, criam leis que geram benefícios ou incentivos fiscais de ICMS e as aplicam até o momento em que são declaradas inconstitucionais, sendo que os contribuintes albergados pela legislação também se aproveitam das benesses legais.

Em segundo lugar, a exigência de unanimidade nos convênios do CONFAZ gera um modelo em que se cria uma espécie de "ditadura da minoria". Isto é, basta que pouquíssimos estados-membros, ou mesmo um único governo subnacional, não concordem com a proposta de benefício ou incentivo fiscal de ICMS a ser criada que a inovação legislativa é rejeitada. Sob o argumento da defesa da harmonia fiscal e econômica, estimula-se um ambiente em que qualquer ideia nova atinente 
a benefícios ou incentivos fiscais de ICMS seja considerada condenável e, portanto, proibida.

Ademais, a imposição da unanimidade na decisão promove a deterioração do pacto federativo, minando a relação de cooperação entre os Estados-membros necessária para a manutenção da República Federativa e para a autonomia administrativa dos governos subnacionais. Frise-se que, em um Estado Democrático de Direito, os governos subnacionais não podem se tornar reféns de decisões com poder de veto de um ou alguns estados-membros, sob pena de se descaracterizar o conceito de Federação, como se esta fosse um mero acordo entre particulares.

Para se enfrentar o problema em debate, percebe-se que dois caminhos poderiam ser percorridos: (i) alteração do art. $2^{\circ}, \S 2^{\circ}$, da Lei Complementar $n^{\circ} 24 / 75$, acabando com a exigência da unanimidade nos convênios do CONFAZ sobre benefícios ou incentivos fiscais de ICMS, abrindo-se espaço para a participação democrática dos Estadosmembros e dando relevo à cooperação na Federação; e (ii) instituição de outro modelo legislativo para atender à orientação do art. 155, § $2^{\circ}$, XII, "g”, da CR/88, criando-se um novo espaço de ação para os governos subnacionais, como, por exemplo, na hipótese de haver protocolos firmados entre os estados-membros ou câmaras de conciliação em que também houvesse a participação da União como membro mediador.

Neste aspecto, deve-se reconhecer que o projeto de Lei Complementar $n^{\circ} .130 / 2014$, em trâmite no Senado, possui um texto substitutivo (Emenda n ${ }^{\circ} .1$ da Comissão de Assuntos Econômicos CAE) que é um avanço para afastar o poder de veto da minoria, criando um espaço mais amplo para o debate sobre o conteúdo da legislação e em consonância com os princípios do Estado Democrático de Direito. 


\section{REFERÊNCIAS}

BRASIL. Constituição (1988). Constituição da República Federativa do Brasil de 1988. Disponível em: $<$ http://www.planalto. gov.br/ccivil_03/Constituicao/Constituicao.htm>. Acesso em: 7 out. 2016.

BRASIL. Lei Complementar $n^{\mathbf{0}}$ 24, de 7 de janeiro de 1975. Dispõe sobre os convênios para a concessão de isenções do imposto sobre operações relativas à circulação de mercadorias, e dá outras providências. Disponível em: $<$ http://www.planalto.gov.br/ccivil_03/ leis/LCP/Lcp24.htm>. Acesso em: 7 out. 2016.

BRASIL. Projeto de Lei Complementar $n^{\circ}$ 130/2014 (PLS 130/2014) com texto substitutivo (Emenda $n^{\circ} 1$ da Comissão de Assuntos Econômicos - CAE). 2014a. Disponível em: <http://legis. senado.leg.br/mateweb/arquivos/mate-pdf/163285.pdf $>$. Acesso em: 3 out.2016.

BRASIL. Superior Tribunal de Justiça. Recurso Ordinário em Mandado de Segurança $\mathbf{n}^{\circ}$ 33524/PI. Re. Ministra Eliana Calmon, Orgão Julgador: S1 - Primeira Seção, julgado em 28 ago. 2013, DJe 7 mar. 2014b.

BRASIL. Supremo Tribunal Federal. Ação Direta de Inconstitucionalidade $n^{\circ}$ 351/RN. Rel. Ministro Marco Aurélio, Tribunal Pleno, julgada em 14 maio 2014c. Disponível em: <http://stf. jus.br/portal/processo/verProcessoPeca.asp?id=307910182\&tipoApp=. pdf $>$. Acesso em: 7 out. 2016.

BRASIL. Supremo Tribunal Federal. Ação Direta de Inconstitucionalidade $\mathbf{n}^{\circ}$ 3421/PR. Rel. Ministro Marco Aurélio, 
Tribunal Pleno, julgada em 05 maio 2010, DJe-096 27 maio 2010, publicado em 28 maio 2010.

BRASIL. Supremo Tribunal Federal. Ação Direta de Inconstitucionalidade $n^{\circ}$ 4481/PR. Rel. Ministro Roberto Barroso, Tribunal Pleno, julgado em 11 mar. 2015, DJe-092 18 maio 2015, publicado em 19 maio 2015.

BRASIL. Supremo Tribunal Federal. Recurso Extraordinário ${ }^{\circ}$ 628075/RS. Rel. Ministro Joaquim Barbosa, Tribunal Pleno, julgado em 13 out. 2011, DJe-228 30 nov. 2011, publicado em 1 dez. 2011.

FERRAZ JUNIOR, Tércio Sampaio. Unanimidade ou maioria nas deliberações do CONFAZ: considerações sobre o tema a partir do princípio federativo. Revista Fórum de Direito Tributário - RFDT, Belo Horizonte, ano 10, n. 59, p. 16, set./out. 2012.

REZENDE, Fernando. Conflitos federativos: esperanças e frustrações - em busca de novos caminhos para a solução. Belo Horizonte: Forum, 2016.

RIBEIRO, Ricardo Lodi. Paternalismo federativo e a competição para a concessão de benefícios fiscais no ICMS e no ISS. Revista Fórum de Direito Tributário - RFDT, Belo Horizonte, ano 10, n. 59, p. 145, set./out. 2012.

VIANA, André Santos. Propostas concretas para o fim da guerra fiscal do ICMS: uma análise consequencialista. Revista Direito Tributário Atual, São Paulo, n. 36, 2016.

Como citar: MARINS, Daniel Vieira. OLIVEIRA, Gustavo da Gama Vital de. A autonomia federativa e o problema da unanimidade nos convênios do CONFAZ. Revista do Direito Público, Londrina, v. 12, 
n. 2, p. 250-272, ago. 2017. DOI: 10.5433/1980-511X.2017v12n2p250

Recebido em: 21/01/2017

Aprovado em: 02/05/2017 